\title{
LETTERS
}

\section{Occupational asthma to solder wire containing an adipic acid flux}

\section{To the Editors:}

We present the first case of occupational asthma to colophonyfree solder wire containing an adipic acid flux, previously only reported in a pharmaceutical factory worker who was in contact with spiramycin powder [1]. The 43-yr-old female presented with rhinitic symptoms in 1992. She had worked as a solderer and desolderer of alternator parts since June 1989. The process used a colophony-free solder wire containing an adipic acid flux from 1996, but, when desoldering, colophony fluxes may still have been present.

From 1998, she experienced a gradual onset of breathlessness and chest tightness, which she noticed was affecting her keepfit. She had had no asthma, hay fever or eczema in childhood, and there was no family history of these conditions. She was a lifelong nonsmoker and gave negative skin-prick test results to common environmental allergens. She started to show nocturnal waking and shortness of breath in the morning, feeling better on days away from work, particularly on holiday. She also noticed that she felt better when not soldering at work. She carried out serial peak expiratory flow measurements four times daily for a total of 4 weeks. When plotted using the Oasys program [2], they showed work-related changes, with an Oasys score of 3.1 (probable occupational asthma; a score of $>2.50$ has a sensitivity of $75 \%$ and specificity of $94 \%$ for occupational asthma diagnosis [2]) and an area between the curves (ABC) score of $15 \mathrm{~L} \cdot \mathrm{min}^{-1} \cdot \mathrm{h}^{-1}$ (an ABC score of $\geqslant 15 \mathrm{~L} \cdot \mathrm{min}^{-1} \cdot \mathrm{h}^{-1}$ has a sensitivity of $69 \%$ and specificity of

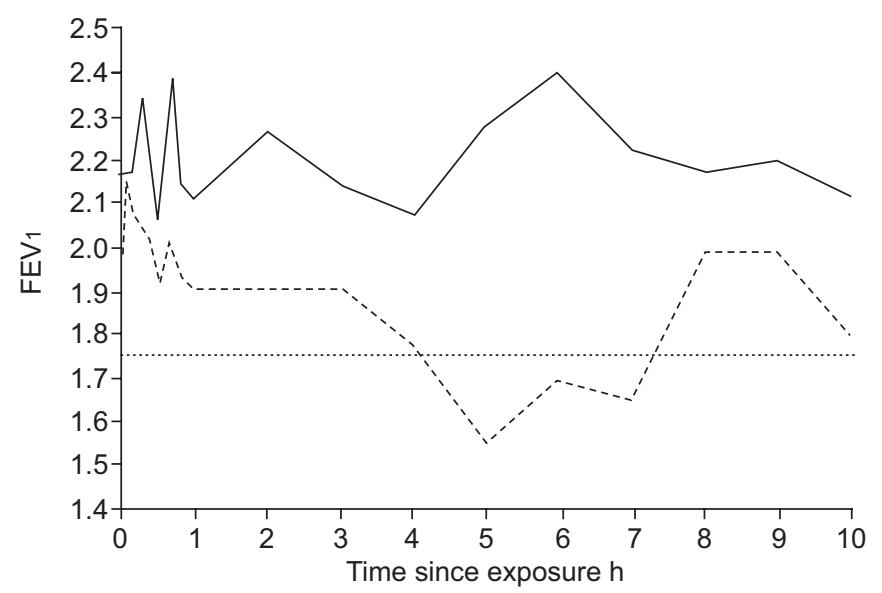

FIGURE 1. Specific inhalation challenge test results (- $\_$: colophony-fluxed solder wire; ------: adipic-acid-fluxed solder wire; …....... $20 \%$ below baseline). FEV1: forced expiratory volume in $1 \mathrm{~s}$.
$100 \%$ [3]). She was admitted for specific inhalation challenge testing to colophony- and adipic-acid-fluxed solder wires. She melted $\sim 1 \mathrm{~m}$ of solder wire (using an iron heated to $170^{\circ} \mathrm{C}$ ) over three challenges, totalling $30 \mathrm{~min}$ for the colophonycontaining wire and $12 \mathrm{~min}$ for the adipic acid wire. The results are shown in figure 1 . She exhibited a late asthmatic reaction after the adipic acid exposure, with her forced expiratory volume in $1 \mathrm{~s}$ falling by a maximum of $28 \%$ from baseline. She showed no reaction to the colophony-fluxed solder wire. Her methacholine reactivity before challenge was $3,450 \mu \mathrm{g}$ methacholine (normal) using the method of YAN et al. [4], halving following adipic acid wire challenge to $1,729 \mu \mathrm{g}$ (mildly hyperreactive).

Adipic acid exhibits an asthma hazard index of 0.75 using the chemical asthma hazard assessment program [5]. Substances with indices of $>0.5$ have a high probability of being an asthmagen. Other non-colophony-based fluxes, such as palmitic acid and dodecanedioic acid, also have high hazard indices (0.92 and 0.94, respectively).

On follow-up, the worker had joined a different company as a toilet cistern assembler. She still showed significant asthma, with occasional nocturnal wakening and a St George's Respiratory Questionnaire score of 50.8. Her methacholine reactivity was normal at $>4,800 \mu \mathrm{g}$.

Thus adipic-acid-fluxed solder wire is a new cause of occupational asthma.

\section{V.C. Moore and P.S. Burge}

Occupational Lung Disease Unit, Birmingham Heartlands Hospital, Birmingham, UK.

Correspondence: V.C. Moore, Occupational Lung Disease Unit, Dept of Respiratory Medicine, Birmingham Heartlands Hospital, Bordesley Green East, Birmingham, B9 5SS, UK. E-mail: vicky.c.moore@heartofengland.nhs.uk

Statement of Interest: A statement of interest for P.S. Burge can be found at www.erj.ersjournals.com/misc/statements.dtl

\section{REFERENCES}

1 Moscato G, Naldi L, Candura F. Bronchial asthma due to spiramycin and adipic acid. Clin Allergy 1984; 14: 355-361.

2 Gannon PFG, Newton DT, Belcher J, et al. Development of OASYS-2: a system for the analysis of serial measurements of peak expiratory flow in workers with suspected occupational asthma. Thorax 1996; 51: 484-489. 
3 Moore VC, Jaakkola MS, Burge CB, et al. A new diagnostic score for occupational asthma. The area between the curves (ABC score) of peak expiratory flow on days at and away from work. Chest 2009; 135: 307-314.

4 Yan K, Salome C, Woolcock AJ. Rapid method for measurement of bronchial responsiveness. Thorax 1983; 38: 760-765.
5 Jarvis J, Seed MJ, Elton R, et al. Relationship between chemical structure and the occupational asthma hazard of low molecular weight organic compounds. Occup Environ Med 2005; 62 243-250.

\section{Response to salbutamol in patients with mild asthma treated with nadolol}

\section{To the Editors:}

$\beta$-blockers (inverse agonists) have an exactly opposite effect to $\beta_{2}$-adrenoceptor $\left(\beta_{2}\right.$-ADR) agonists and are currently contraindicated in asthma. This results from the fact that the acute administration of these drugs can produce bronchoconstriction by blocking the bronchodilating effects of endogenous adrenaline, or by inactivating constitutively active $\beta_{2}$-ADRs, and can worsen asthma symptoms [1]. In fact, published accounts have shown that acute $\beta$-blocker use can, but will not always, precipitate airway constriction in patients with asthma [2]. Nevertheless, there are compelling uses of $\beta$-blockers in asthmatics, such as in heart failure and after myocardial infarction. The effect of chronic administration of $\beta$-blockers in asthma has remained unknown until recently, when studies on a murine model of asthma showed that, while acute (singledose) administration of $\beta$-blockers increased airway hyperresponsiveness (AHR), their chronic (28-day) administration had an opposite effect and decreased AHR [3]. Furthermore, recent data demonstrate that chronic $\beta$-blocker treatment produces broad anti-inflammatory effects, and especially dramatic effects on airway epithelium and mucous metaplasia [4, 5]. More recently, our group has further confirmed the pivotal role that $\beta_{2}$-ADR has on mucous metaplasia using a $\beta_{2}$-ADR null mouse [6]. Based on these findings in the murine asthma model, we investigated the role of chronic administration of nadolol (a non-selective $\beta_{1}$ - and $\beta_{2}$-blocker) on airway hyperresponsiveness in an open-label study of 10 subjects with mild asthma [7]. We demonstrated that nadolol produced a dose-dependent increase in the PC20 (provocative dose causing a $20 \%$ fall in forced expiratory volume in $1 \mathrm{~s}$ (FEV1)) methacholine when administered over 11 weeks. However, a concern that remained is whether these subjects treated with nadolol can still respond to short-acting $\beta_{2}$-ADR agonists for rescue of bronchospasm [8]. In fact, one concern is that nadolol "may block bronchodilation produced by endogenous or exogenous catecholamine stimulation of $\beta_{2}$ receptors" (Corgard ${ }_{\circledR}$ product insert; King Pharmaceuticals, Inc., Bristol, TN, USA).

We have now completed our second open-label study of chronic nadolol in subjects with mild asthma who are not on controller therapy $(n=10)$ (table 1$)$. Both studies were approved by the Baylor College of Medicine Institutional Review Board (Houston, TX, USA) and informed consent was obtained from all subjects. Starting at a daily dose of $1.25 \mathrm{mg}$ and ending at a maximum daily dose of $40 \mathrm{mg}$, nadolol dose was escalated on a biweekly basis based on predetermined safety, lung function, asthma control and haemodynamic parameters. Subjects were treated for a total of 13 weeks with nadolol ( $\geqslant 3$ weeks on their final tolerated dose). Seven out of the 10 subjects were able to be escalated to $40 \mathrm{mg}$, one tolerated

\section{TABLE 1 Baseline demographics and characteristics of study population}

\begin{tabular}{|c|c|c|c|c|c|c|}
\hline Subject no. & Sex & Age yrs & Race & Baseline FEV 1 \% & Baseline $\mathrm{PC}_{20}$ & Final dose $\mathrm{mg}$ \\
\hline 1 & $\mathrm{~F}$ & 48 & Black & 84 & 3.576 & 40 \\
\hline 2 & $\mathrm{~F}$ & 24 & White & 98 & 3.621 & 40 \\
\hline $4^{\#}$ & M & 27 & Hispanic & 81 & 3.479 & 1.25 \\
\hline 5 & $\mathrm{~F}$ & 49 & Hispanic & 86 & 0.112 & 40 \\
\hline 8 & $\mathrm{~F}$ & 26 & Hispanic & 91 & 0.471 & 40 \\
\hline 9 & $\mathrm{~F}$ & 18 & Asian & 83 & 0.372 & 40 \\
\hline 10 & $\mathrm{~F}$ & 29 & White & 114 & 6.418 & 40 \\
\hline Mean \pm SEM & & $32.6 \pm 3.6$ & & $90.7 \pm 3.3$ & $1.18^{\circ} \pm 1.53^{+}$ & $29.6 \pm 6$ \\
\hline
\end{tabular}

${ }^{\#}$ : subject excluded because of an asthma exacerbation early in the study; ${ }^{\bullet}$ : geometric mean; ${ }^{+}$: geometric SEM 